\title{
Influencing the Influencers: The Role of Mothers in IT Career Choices
}

\author{
Rosemary Stockdale and Therese Keane \\ Swinburne University, Melbourne, Victoria, Australia ${ }^{1}$
}

\author{
rstockdale@swin.edu tkeane@swin.edu.au
}

\begin{abstract}
This paper reports on the outcomes from a pilot study targeted at mothers of school children in Melbourne, Australia. The aim of the study was to engender a positive view of technology in the participants and to introduce the concept of Information Technology (IT) as a potential career. Mothers were given the opportunity to develop basic IT skills and learn about different IT career pathways for their children with an emphasis on their daughters' choices. Mothers were offered an evening course over a four week period that was designed to introduce them to a range of social media and Web 2.0 tools. Their opinions were documented using both questionnaires and informal discussions. It explored whether their attitudes towards IT can be changed by up-skilling and introducing them to the technologies their children commonly use. The findings of the pilot study suggest that addressing this demographic has the potential to make the participants question their pre-conceptions about IT careers for women.
\end{abstract}

Keywords: gender and IT, information technology professionals, mothers, parental influences

\section{Introduction}

This paper reports the motivations for, and outcomes of, a pilot study targeted at mothers of school children. The aim of the project was to give mothers a positive view of Information Technology (IT) and open them to the idea of IT careers for their children, particularly their daughters, as studies have reported on the maternal influences in the career development process (Bleeker \& Jacobs, 2004; Lawson, Crouter, \& McHale, 2015; Whiston \& Keller, 2004).

Information Technology is not a commonly sought after career for young women (Deloitte

(CC BY-NC 4.0) This article is licensed to you under a Creative Commons Attribution-

NonCommercial 4.0 International License. When you copy and redistribute this paper in full or in part, you need to provide proper attribution to it to ensure that others can later locate this work (and to ensure that others do not accuse you of plagiarism). You may (and we encourage you to) adapt, remix, transform, and build upon the material for any non-commercial purposes. This license does not permit you to use this material for commercial purposes.
Access Economics, 2016). The number of females graduating with an IT degree has consistently declined since the 1980s and now accounts for less than $18 \%$ of IT graduates (Hutchinson \& Tadros, 2014; NCWIT, 2014). According to the OECD (2014, 2015b), there are five times more men than women studying computing at tertiary level. These figures are replicated in the IT industry where women currently constitute a small part of the workforce $-24 \%$ in the United States, $18 \%$ in the UK, and 28\% in Australia (Deloitte, 2016; Deloitte Access

\footnotetext{
${ }^{1}$ The authors thank Ms Sharmini Thurairasa, Mr. William Gaunt, Ms Kirstie Ismail, and Ms Esther Lausberg who all contributed to the running of the pilot programme on which this paper is based. We also thank Mr. Tony Hirst, the Principal of Emmaus College, for his support.
}

Editor: Jo Coldwell-Neilson

Submitted: October 9, 2016; Revised: December 9, 2016; Accepted: December 11, 2016 
Economics, 2016). This lack of diversity in IT has repercussions for organisations and for society.

There is increasing evidence that diversity in the workplace has a positive influence on productivity (Australian Computer Society, 2015; Deloitte, 2016). For example, Herring (2009) reports that organisations with high levels of gender diversity in teams have higher sales revenues, more customers, and greater profitability than companies with predominantly male teams. Finding capable and confident people with IT skills is very difficult, and many employers struggle to recruit employees, particularly as the talent pool is restricted by the lack of qualified women. Encouraging more women into IT university courses would lead to an increase in both the size and diversity of a country's skilled workforce and address the growing shortfall of IT professionals in industry.

Multiple and different approaches are needed to address ways of increasing the uptake of IT studies in universities. This paper reports on a pilot study that aims to investigate the role of mothers in influencing schoolchildren (and particularly daughters) to consider IT as a study and a career option. Drawing on Trauth's Theory of Individual Differences (Trauth, Quesenberry, \& Morgan, 2004), this paper details an initiative that examines underlying factors that affect women's participation in IT careers. The theory posits that social shaping of gender and IT operates at an individual level and is influenced by a range of factors such as demographics, personal influences, and cultural attitudes (Trauth et al., 2004). The influence of family and friends, as well as encountered attitudes towards women and women working in IT, influence a person's likelihood to consider an IT career. This suggests that parents have an important role to play in influencing individual choices of their children. Mothers' ingrained gender-role perceptions can have significant influence on the selection of their daughter's career choice (Fiebig \& Beauregard, 2011). This study investigates whether mothers' attitudes towards IT can be changed by up-skilling them and introducing them to the technologies their children commonly use. The project also included informal discussions about IT as a career for women. The emphasis on up-skilling the mothers is based on the idea that women confident in using everyday IT will break down the barriers that currently exist in choosing IT careers (e.g., influences and attitudes). The findings of the pilot study suggest that addressing this demographic has the potential to make the participants question their pre-conceptions about IT careers for women.

The paper is structured as follows. The literature review addresses existing research in this area and the influence of mothers in career choices for females interested in IT. It then details the pilot study, and the findings are presented and discussed. Finally, avenues for further research are reflected upon.

\section{Literature Review}

\section{Gender Diversity in IT}

Information Technology permeates society at every level and plays a key role in organisations across a comprehensive range of industries. There are several career paths available to IT graduates across a spectrum from the very technical through to business-orientated roles (Deloitte Access Economics, 2015). However, the workforce has remained a male domain despite many initiatives to encourage women to consider a career in IT (Bailie, 2015). Finding capable and confident people with good communication and IT skills is very difficult, and many employers find it challenging to recruit suitable employees. The shortfall in IT professionals across many countries is set to continue as enrolments in Information Technology courses and subjects at both tertiary and secondary schools have been declining for many years (Commonwealth of Australia \& Australian Workforce and Productivity Agency, 2013; Panko, 2008).

In 2011, it was found that only 7\% of Information Technology degrees in the United Kingdom were taken by female students, and women represent only $20 \%$ of the workforce in technology 
departments (Milman-Hurst, 2011). In Australia, employers, universities, and the Government have acknowledged a skills shortage and are concentrating their efforts to address it (Australian Computer Society, 2008; Deloitte Access Economics, 2015; Ridley \& Young, 2012). There have been many reports and investigations into the reasons for the shortfall and the identified factors are many and varied. For example, the skills shortage can be attributed to a decrease in the number of students enrolling in IT courses post-secondary school or graduates not considered to be employable because they are not work ready. Further factors include lack of job security, the need to constantly update skills to match market demand, the negative perception of workers as nerds or geeks, perceptions the profession is boring, or not understanding Information Technology as a discipline to be able to make an informed career decision (Australian Computer Society, 2008, 2012, 2015; Google, 2014; Koppi et al., 2008; Sáinz, Pálmen, \& García-Cuesta, 2012; Thomas \& Allen, 2006).

The lack of gender balance has a significance effect on the pool of skilled people from which employers can draw. It also becomes somewhat of a self-fulfilling pattern of inequality as the lack of female IT workers strengthens the negative perceptions of an unfriendly and unattractive profession (Galyani Moghaddam, 2010; Hart \& Stockdale, 2009). Such negative views of IT are sometimes seen to begin very early in life and Milman-Hurst (2011) suggests that the building of a gender balance within the IT environment should begin with children as young as five by promoting early exposure to technology and promoting positive role models. The issue of role models starts in the home where parental influences are important and the lack of women in IT may be seen to reflect on the attitudes of subsequent generations (Adya \& Kaiser, 2005). Popular culture promotes another source of role models, and the portrayal of female IT experts in film and television is rare and stereotypes them with the unattractiveness of the nerd perception (Cheryan, Master, \& Meltzoff, 2015; Thomas \& Allen, 2006).

Other studies have identified the fall in girls' interest in IT as occuring in secondary school where students start selecting their subjects and their respective academic and vocational pathways (Sáinz \& Eccles, 2012; Zagami, Boden, Keane, Moreton, \& Schulz, 2015). Researchers have reported that more male students tend to pursue scientific and technological studies in contrast to females (Bandura, Barbaranelli, Caprara, \& Pastorelli, 2001; OECD, 2015a). Despite being academically capable and having aptitude, females are not attracted to IT careers. They often perceive themselves as less competent in IT than other subjects and lack confidence in their own IT abilities (Bandura et al., 2001; Hargittai \& Shafer, 2006; Hilbert, 2011; Singh, Allen, Scheckler, $\&$ Darlington, 2007). This was not always the case as women studying computer science in the 1980 s accounted for $37 \%$ of the cohort. Glass (2012) remarks that the fall in numbers of female students began as universities moved Computer Science courses from Liberal Arts schools into Engineering faculties, although further research is needed to attribute any cause and effect to these events.

In order to attract more females to the IT profession, there is a need to focus on how to make the study of IT attractive to secondary school students (Wang, Hong, Ravitz, \& Ivory, 2015; Yansen, 2014; Zagami et al., 2015). The situation is complex to remedy (Ridley \& Young, 2012) and requires intervention to influence perceptions of careers in the IT workforce (Quesenberry \& Trauth, 2012). Quesenberry and Trauth (2012) and Sáinz and Eccles (2012) suggest that, given parents and teachers are very influential in young adolescents' lives, perhaps it would be ideal to begin this campaign in middle school as this is when girls form opinions about their interest or lack of interest in computing subjects and/or IT careers (Vitores \& Gil-Juárez, 2015).

Moreover, parents have been identified as very influential in the counselling of their children in non-traditional careers such as entering the IT profession (Adya \& Kaiser, 2005; Babin, Grant, \& Sawal, 2010; Dickhäuser \& Stiensmeier-Pelster, 2003; Quesenberry \& Trauth, 2012). Just as fathers condition their sons, mothers do the same for their daughters in terms of academic influence 
(Sáinz et al., 2012). Adya and Kaiser (2005) also found that children close to their parent of the same sex often reflect the career choices of that parent. Theoretical and empirical literature also supports the importance that mothers have in their daughters' career development (Bleeker \& Jacobs, 2004; Lawson et al., 2015; Paa \& McWhirter, 2000; Whiston \& Keller, 2004). Mothers are keen to encourage their daughters into tertiary education and there is a growing gender gap in enrolments with women now accounting for $60 \%$ of students in US colleges (Bissell-Havran, Loken, \& McHale, 2012). Therefore the problem in IT would not appear to be educational ability but attributable to other reasons.

To identify such reasons, Ridley and Young (2012) examined existing theories that have been used to explain the gender gap in non-traditional female careers. They considered three theories that have been used to explain the gender imbalance in the IT workforce - the essentialist, social construction, and individual differences theories of gender. The Essentialist Theory, which stems from psychology, hypothesizes that men and women have fixed and different natures (Adam, Howcroft, \& Richardson, 2004; Howcroft \& Trauth, 2008; Trauth et al., 2004). It posits that there are differences between women's IT responses and uses and those of men, even after controlling for confounding variables from organisational behaviour research. The second theory, that of Social Construction, proposes that people act and behave according to the culture in which they are born and raised. Therefore, because IT is perceived as a male dominated domain it is incompatible with female social construction, which in turn supports society viewing this field as male dominated (Hart \& Stockdale, 2009). Ridley and Young's (2012) findings suggest that the Essentialist Theory has little credence, and the Theory of Social Construction does not address individual differences, but assumes inherent male and female traits. The third theory examined, Individual Differences, bridges the gap and provides an alternative way to examine the IT gender gap.

The Theory of Individual Differences (Trauth et al., 2004) draws on previous research on gender and IT and emphasises the differences within genders rather than between them. The theory "looks at men and women as individuals, who experience a range of different social-cultural influences which shape their inclination to participate in IT in a variety of ways" (Trauth et al., 2004, p. 116). The Individual Differences Theory has three constructs: personal data (including personal demographic, lifestyle, and workplace data), shaping and influencing factors (including personal characteristics and personal influences), and environmental context (including cultural influences, geographic, economic, and policy data).

What is interesting in terms of this theory is the recognition of social-cultural influences that affect participation in IT. This is a facet of the theory that becomes more interesting as IT moves into the social space and new technologies bring the facility of co-sharing, collaboration, and social interaction into the environment (Parameswaran \& Whinston, 2007). These are factors that are seen in women's use of IT along with the need to embed IT in daily life rather than identify it purely from a technical viewpoint (Buchmüller, Joost, Bessing, \& Stein, 2011). This holistic approach to IT is not well recognised, as noted by Gillard, Mitev, and Scott (2007) in their examination of a UK consortium's attempt to bring more women (single mothers) into the IT workforce. The consortium of government, major IT companies, and universities envisaged providing women with IT skills and knowledge necessary to setup their own businesses. Gillard et al. (2007), found that the initiative had limited success as the institutions saw and addressed the problem as a technical one without due consideration of the needs and responsibilities of the women.

Further influences noted in the theory are those of personal characteristics and personal and cultural influences. Given that mothers are seen to be strong influences in their children's lives (Adya \& Kaiser, 2005; Paa \& McWhirter, 2000; Sáinz et al., 2012) this pilot study undertook to examine whether up-skilling the mothers in IT use would influence their own perceptions of IT. This may in turn affect the way they perceive the environment of IT and the potential for interesting careers for their daughters. 


\section{Details of the Study}

The pilot study was carried out over a four-week period, with weekly 90 -minute sessions held in a high school computer laboratory. The high school principal and his staff were very supportive of the initiative and volunteered to advertise and then host the workshops for mothers of their students and also for the mothers of the local feeder primary schools after school hours. The high school allowed the study team and participants to use their computer laboratory and provided network and Internet access for the class. The high school is situated in the outer eastern suburbs of Melbourne, Australia. Melbourne is an affluent city with high levels of computer access and a thriving IT industry. No demographic details of the participants were recorded and the only criteria was that participants had children in the target schools and an interest in learning more about IT.

Three academics developed the pilot initiative and three undergraduate students (two female and one male) from a Bachelor of IT course were recruited as Student Tutors for the twelve mothers who enrolled in the four workshops. The curriculum for the course was developed from a series of topics that was then informed by requests from the participants. The key topics addressed in this way were creating and using an online presence through email and Facebook, creating a blog, opening and using a Twitter account, and basic website creation skills using a platform called Weebly. These key topics were selected in consultation with the Student Tutors, who are representative of the younger generation and conversant with their use of common applications. This enabled the mothers to understand and appreciate the online activities their children engage in on a daily basis.

The course remained informal with participants able to progress at their own rate, work with friends, and take tea breaks as required. The Student Tutors worked with small groups and individuals to troubleshoot problem areas. At each workshop, at least one academic was present to support the Student Tutors and the participants and to lead group discussions.

\section{Methodology}

In this preliminary step of a longer-term project, the aim was to develop the concept of parental influence as a major determinant of making IT an acceptable, or even desirable, career path for girls. The initial emphasis was on up-skilling the women participants in IT in an informal and non-challenging environment. The objective was to get them familiar and confident with the applications that their children use. Discussions on gender and IT and the potential for careers were informally introduced near the end of the course when more targeted questions were included in the focus group discussions. The four-week course was designed to introduce the mothers to a range of social media and Web 2.0 tools and to chart their opinions as they proceeded through the weeks. There were two objectives of the pilot study:

1. to pilot a programme of IT learning that appeals to mothers and enables them to gain enjoyment and confidence in a digital environment.

2. to determine the potential of such hands-on experience to influence mothers' ideas of IT as a career of choice for their children, with a particular emphasis on daughters.

In the pilot stage, gender was not identified as a key driver of the initiative and no differentiation was made between mothers of male and/or female children.

\section{Data Collection and Analysis}

The pilot was limited to twelve participants and the phases of data collection were:

- observation and on-going informal discussions with participants during the classes 
- a feedback questionnaire given to participants at the end of the last evening

- unstructured interviews with the three Student Tutors after completion of all the workshops

- an end-of-course focus group of all participants and team members.

The feedback questionnaire was used to gather data on why the women chose to take the course and what they enjoyed and found challenging and asked for general feedback on the initiative.

The participants were asked to reflect on what they saw as the challenges from their perspective, what they had learned, and what the main points of enjoyment had been for themselves. They were then requested to reflect on their own personal learning and their feedback to further develop the workshops. This concerned the running of the course and their perceptions of how the attendees learned from the experience.

The Student Tutors also contributed feedback on future development ideas for extending the initiative. The three academic staff members of the team pooled experiences over the four weeks of the course and reflected on the learning. The focus group covered more wide-ranging topics such as the perception of IT as a career for women and the use of technology in the workplace. The discussion that was held on the final workshop was digitally recorded to allow for data validation and sharing between researchers. The group discussions in this study were informal, although the questions posed by the academics were semi-structured and followed the method for semistructured interviewing techniques (Wellington, 2000). This ensured that aspects of the investigation which came up during the discussion could be further explored, allowing the researchers to appreciate the perspective of the group (Patton, 2002).

The data from the collective sources were analysed through open coding, loosely based on the questions in the informal questionnaire and repeated in an informal way during the focus group. These questions addressed the motivations of the participants in attending the course, their perceptions of IT - post course completion - and their learnings from the course. Input from the Student Tutors and the academic team was included in the coding. Each of the academics analysed the inputs and then met collectively to discuss the analysis of data several times to ensure internal validity of the process and agreement about the interpretation.

\section{Upskilling Participants}

Of the ten participants who completed the feedback survey, one person had no knowledge of IT, while the others were all self-taught and had limited capabilities. The extent of their experience was primarily a basic knowledge of Microsoft Office and PowerPoint acquired through work. One participant had some skills in using social media as she had a Facebook and a LinkedIn account that was set up by a family member. There were two reasons for participation in the course;

- learning about IT from "a practical course that addressed a lot of things that I was interested in but scared to try"

- learning "more about programs that my children use and talk about".

Learning about IT was mentioned by all the participants who noted their difficulties in acquiring computer knowledge and their frustration at their lack of knowledge about how to use social media. Keeping up with their children was also a common theme with the mothers who were concerned that they knew little about what their children were doing on their computers. This anxiety was fuelled by frequent media reports on the dangers of social media and the parents' perception that their children were unsupervised in the social media space. 
One participant expressed disappointment with the course and felt she did not learn much, although this was not discussed with any member of the team. This participant was the only attendee with a Facebook page and a LinkedIn site. The other participants enjoyed learning in a "friendly environment" and were pleased with their progress in social media "setting up blogs, a website and Facebook". Other positives were the ability to use applications and "explore programs without have to buy/subscribe" and learning "hands on problem solving and confidence building".

The participants noted their key challenges from the course as frustration in logging into applications, remembering passwords, and trying to learn as much as possible in a short period of time. The different levels of ability meant that some participants struggled in one or two areas and there were concerns that topics could not be addressed in more depth although it was recognised that "some people got the content quickly". Suggestions were made that there should be "a little more guided exploration for those who have limited IT knowledge" and that each topic should be introduced more formally to the class, followed by hands-on activities. One participant commented that "it would be good to use my own computer in the course".

The request for general comments from participants elicited an appreciation of the work of the Student Tutors who were seen as "very informative and friendly" and the mothers "liked the students being part of the class". One participant reflected that she was "amazed how much I learnt as a mature age person".

\section{Participants' Perceptions of ICT}

A focus group in the last workshop allowed for participants to reflect on IT and their views in a very general and informal way. The aims were to find out what the women felt they had learned, if they were more confident with experimenting with different applications, and their overall perceptions of IT. The conversation covered in some detail how the women present had not been encouraged to use IT as young people. They were self-taught in basic IT such as Microsoft Word because they needed it for work or for tasks at home. None of the women had explored IT as a matter of interest and had learned their skills as and when needed. They confirmed the workshop had provided them with an environment where they felt more confident about "playing around" with applications and trying things for themselves. They agreed that the workshop had engendered confidence so they felt they could "have a go" at experimenting with new applications without worrying about adverse outcomes. They also expressed pleasure in being able to talk to their children about social media and had gained an appreciation of some of the ways in which they can establish themselves with an online presence.

An interesting thread of conversation in the focus group was initiated by a mother who worked in the health sector. She led a discussion thread into IT in the workplace by sharing an example of a recent system that had been installed in her workplace. She was dismayed by the inadequacy of the system, the abysmal user design, and asserted that the system was not fit for purpose. She attributed this to the macho culture of the IT contractors. The conversation broadened out to include other women who felt that IT was very gendered in its design and implementation and would work much better if there were gender diverse teams involved. When the participants were asked whether they would consider advising schoolgirls to aim for an IT career to mitigate this macho culture, there was agreement that it would be "a good thing". However, the school curriculum and the parents' own lack of knowledge about IT career pathways were held to be inhibitors to increasing interest amongst girls. Further discussion ensued regarding the ubiquity of IT in the workplace and whether girls would be more likely to succeed if they were highly IT literate.

None of the women present were aware of Information Systems courses and the use of IT in a business sense as a university study pathway, although they were enthusiastic about the idea. One 
commented that IT at university was seen to be about Computer Science and the "girls did not like that much" because it was too "geeky". One participant did comment that her sister had studied computer science and had enjoyed university greatly because she was an extrovert, mixed well with her male cohort, and had since done well in her career.

Several of the women agreed with a participant who noted that the Student Tutors' own perceptions of IT were that it is an integral part of their generation's lifestyle. As a generational change, this would improve females' perception of IT and open further opportunities to embrace a career in this area. The involvement of the Student Tutors was very positive and the participants recognised that the Student Tutors had influenced their own perceptions of IT being a good career path. At the very least, it was held that girls would need to be tech savvy in the workplace in a way that their mothers are not. Overall, the participants felt that they would be more confident about having IT-based conversations with their children in both the social sphere and as a facet of career planning than they would previously have done.

\section{Reflections of the Research Team}

The research team of three academics absorbed feedback from both three Student Tutors and the participants during the four weeks of the course. The three Student Tutors were interviewed by a member of the research team after the course finished.

\section{Student tutor feedback}

Feedback from the Student Tutors was valuable and well considered. In regard to the structure of the workshops, all three Student Tutors agreed that the participants "enjoyed the sessions, and were keen to learn. They indicated that they found the written tutorial guides to be useful, took notes, considered how the content they learned could be used in other contexts (leisure, work, personal projects etc.), so it was relevant." The Student Tutors saw that the participants' takeaways from the initiative were that IT is "super useful" and does not have to be complicated or difficult, but just takes time to get used to and they need to "fiddle around" more. They tried to impart the message that security and privacy are serious issues and that people should learn how to take steps to improve their own privacy/security settings. Participants, they believed, had learned that you can and should ask for help when it comes to IT without fear of being seen as stupid and that "working with IT can be a pleasant surprise".

Importantly, the Student Tutors had endeavoured to impart the idea that the mothers should be able to talk to their children about IT issues. This latter point led to further interesting input from the Student Tutors that while they acknowledged that the technical sessions were practical, interesting, and useful, they felt that they did not convey the totality of IT. They believed that there should be a greater message of the interpersonal and social dimensions and "think technical sessions may be better viewed as a complement or supportive, secondary element to the core of these kind of sessions (where the core consists of presentations, discussions, people-related content...) I think even relationship advice based on research, or run by established groups, would fit really well here." These views were articulated by all three Student Tutors and appear to arise from their concerns that "some mothers misunderstood the purpose of the sessions". For example, during a Facebook-related session, one mother jotted down notes about her daughter's Facebook page in order to go home and raise those points as an issue. One Student Tutor felt that such an action would be counter-productive and another saw that to "take notes in order to scold their daughters/relatives" contravened an idea of the workshops to "facilitate a healthy and mutually understanding 'conversation' between mothers and daughters regarding IT'. The suggestion from one of the Student Tutors was to introduce "informative, holistic presentations, and talks about jobs and women's experiences relating to IT jobs would probably be a powerful aid in broadening the participants' perspective of what it means to work in IT." Another of the Student 
Tutors suggested having female IT professionals come and talk to the workshop participants. These ideas both reflected the Student Tutors' commitment to the idea of increasing gender diversity in IT through these workshops as well as their view of IT as an integral part of the social fabric of their lives.

\section{Academic team feedback}

Not every member of the Academic Team was present every week, but initial reflections were consistent and lessons were learned from the pilot that could be applied to the ongoing initiative. In particular, it was agreed that a more structured approach to each lesson was required. While trying to retain an informal and friendly, non-threatening environment the need for greater structure in the course was underestimated. Although cheat sheets were provided (e.g., How to get started with GoogleSites) in class, the participants did not use them at the time and relied on the Student Tutors to guide them through. (However, the Student Tutors did record that participants found the sheets useful at home.) This was only possible because of the high ratio of team members to course participants and in a larger project a more structured, task orientated approach would be needed. Indeed, participants indicated that this would be welcomed and may reflect the different learning styles from the participants' educational experiences compared with the current university cohort. Topic wise, the concentration on Web 2.0 and social media applications was

good. Facebook, Twitter, GoogleSites, creating a blog, and building a website were the key areas covered. Given the time constraints of four 90-minute classes and the lack of confidence in many of the participants, the topics covered appeared to be pitched well. Participants were most keen on the applications where their children were active, particularly Facebook and Twitter. However, two participants were very keen on creating blogs to use for their own work purposes and several related what they were learning to their work situations. This was an aspect of the participants' learning that the research team did not consider. The demographics of the school reflect the profile of the participants who are working parents, many of them in highly responsible roles (e.g., physiotherapist, office manager, and teacher). That professional working women have relatively low IT skills is a consideration the team had not absorbed prior to the course. This has implications for how to recruit for future courses and how to address the gap in such skills.

The decision to employ the students as tutors in the class was initially based on the idea that they would present the Generation Y view of technology and resonate as closely aligned with the participants' own children. They proved to be excellent both in presenting the technical teaching to the mothers and in their ability to relate the role of IT within society. All three Student Tutors were very articulate in their advocacy of IT being an integral part of their social and interpersonal activities. They did not see learning IT skills as a measure of technical ability or the accumulation of work skills, but as a part of their literacy that contributes to relationship building, work opportunities, and an enabler. Whether this is a result of their past experiences and relates to the constructs of their individual differences is an area for further exploration with them.

\section{Moving Forward}

The main aim of this pilot study was to see if mothers of school-aged children would engage with technology to gain enjoyment and confidence in a digital environment. This would enable an examination of whether such up-skilling would influence their attitudes towards IT and potentially contribute to parental influence in the study/career choices of their children. The pilot study has raised many questions regarding the future of this study and has allowed consideration as to whether this initiative has the potential to change the perception of the participants to the extent that they, in turn, influence their (female) children. Overall, there were some positive aspects in the way the participants were able to reflect on their greater ease with IT and on how it led them to reflect on how it could be an excellent career choice for their children. 


\section{Lessons from the Pilot Study}

There were several points raised by the pilot study that have led to the team reflecting on how things could have been done differently. The pilot also enabled the team to identify issues that were not considered in the initial planning. In planning the workshops, the need to present a more structured approach and to develop more materials such as guides and workbooks was acknowledged. Introducing each topic with an overview of how and why the application/tool has been developed and the contexts in which it is used would enhance understanding and aid learning.

The issue of the skill levels of women in the workplace was also identified as a factor to be considered in raising confidence levels and generating more understanding of IT and its role in the workplace as well as the social environment. Therefore, greater attention should be paid to the demographics of the participants, perhaps using a pre-workshop questionnaire. Their learning in the workshop increased participants' confidence, and it would be of interest to see how this impacts of their use of technology into the future. One suggestion is to create a blog in the workshops that is kept alive on completion to create a community of participants to encourage each other on pursuing ongoing learning in the IT space.

Note was made of the Student Tutors' perceptions of IT being a facet of their own lives and not a specific academic discipline divorced from their social and relationship development. This accords with recent studies into the examination of IT as a social product with implications of gender neutrality, social values, and the need for soft skills when considering the gender gap (Galyani Moghaddam, 2010; Gillard et al., 2007). In terms of this study, it means that the workshops need more input on the how and why of technology and not just the acquisition of skills. This would enhance the experience of the participants and perhaps give them greater insights into the levels of digital literacy and social computing experienced by their children.

\section{Developing the Study}

The main question arising from the pilot study is whether there are sufficient outcomes to indicate that there is the potential to alter career choices of female students. The pilot study indicates that a larger scale, more targeted programme aimed at mothers could affect the way schoolgirls experience and perceive IT. This would require a long term study tracking a specific number of schools, and it would seem to be important to include the feeder primary schools in the initiative. The study would need to be integrated with visits to the schools by IT students studying at university and academic staff (to give the class careers talks, etc.) to form a community and create an ongoing relationship.

The planned longitudinal study will take an action research approach that will build a connection between problem solving in real life situations with a relationship to theory and its development (Baskerville, 1999). McKay and Marshall (2007) state "action research involves a simultaneous preoccupation with both taking action to resolve a problematic situation and with researching into and learning from the attempt at problem resolution or improvement" (p. 138).

An action research approach will require further research into the Theory of Individual Differences (Trauth et al., 2004) and examine the constructs empirically through extensive interviews with all stakeholders such as IT professionals, students, and parents. This would support theory development alongside addressing the problematic situation of gender and IT at the university level. Further research is required into what are the influences and environmental constructs that affect career choices in IT and who are the influencers and shapers of individual differences. There is existing literature that indicates that parents, and particularly parents of the same sex as the child, are able to influence study and career choices (Adya \& Kaiser, 2005; Sáinz et al., 2012). Other influences would need to be identified; however, changing the way women (in this case mothers) perceive IT has the potential to have an effect on diversity in the IT industry. 
The workshops have garnered interest from a number of people including those who work with disability groups and immigrant resettlement. This suggests that there is widespread recognition that greater knowledge of technology and an ability to engage with IT are necessary skills to have in the $21^{\text {st }}$ century, particularly across all levels of education and in the workforce (Crockett, Jukes, \& Churches, 2012; Keane, Keane, \& Blicblau, 2016).

\section{Conclusions}

This pilot study was conducted to investigate whether more familiarity with information technology and social media would make mothers more aware of IT career paths for their daughters and more positively inclined to recommend such careers. Although the study was limited to a small cohort of participants, the mothers showed enthusiasm towards the skills they picked up in the workshops. Participants wanted to know more about social networking tools and the issues surrounding this, which showed that they realized they needed to be connected with their family, and particularly with their children, to know what was happening in their world. Although the participants expressed an interest in the idea of IT as a career path for their children, it was not possible to evaluate the effectiveness of long term actions within the confines of the pilot study. More research needs to be conducted to evaluate women's views on gender-equal distributed responsibility in the ICT workplace and their influence on their daughters. Research on perceptions of maternal expectations of their daughters during adolescence is much needed to be able to make more inroads into perceptions of solving the issue of gender imbalance in the ICT workplace.

\section{References}

Adam, A., Howcroft, D., \& Richardson, H. (2004). A decade of neglect: Reflecting on gender and IS. New Technology, Work and Employment, 19(3), 222-240.

Adya, M., \& Kaiser, K. M. (2005). Early determinants of women in the IT workforce: A model of girls' career choices. Information Technology \& People, 18(3), 230-259.

Australian Computer Society. (2008). Australian Computer Society's Submission to the Australian 2020 Summit - ICT Skills in Australia.

Australian Computer Society. (2012). Australian Computer Society ICT statistical compendium. Retrieved from http://www.acs.org.au/_ data/assets/pdf_file/0014/13541/2012_Statcompendium_final_web.pdf

Australian Computer Society. (2015). The promise of diversity: Gender equality in the ICT profession. Retrieved from http://acs.org.au/_data/assets/pdf_file/0003/87681/ACS-Gender-Equality-FINAL.pdf

Babin, R., Grant, K. A., \& Sawal, L. (2010). Identifying influencers in high school student ICT career choice. Information Systems Education Journal, 8(26), 1-18.

Bailie, F. K. (2015). Women who make a difference: Role models for the 21 st century. ACM Inroads, 6(2), 36-43.

Bandura, A., Barbaranelli, C., Caprara, G. V., \& Pastorelli, C. (2001). Self-efficacy beliefs as shapers of children's aspirations and career trajectories. Child Development, 72(1), 187-206.

Baskerville, R. L. (1999). Investigating information systems with action research. Communications of the $A I S, 2(3 \mathrm{es}), 4$.

Bissell-Havran, J. M., Loken, E., \& McHale, S. M. (2012). Mothers' differential treatment of adolescent siblings: Predicting college attendance of sisters versus brothers. Journal of Youth and Adolescence, 41(10), 1267-1279.

Bleeker, M. M., \& Jacobs, J. E. (2004). Achievement in math and science: Do mothers' beliefs matter 12 years later? Journal of Educational Psychology, 96(1), 97.

Buchmüller, S., Joost, G., Bessing, N., \& Stein, S. (2011). Bridging the gender and generation gap by ICT applying a participatory design process. Personal and Ubiquitous Computing, 15(7), 743-758. 
Cheryan, S., Master, A., \& Meltzoff, A. N. (2015). Cultural stereotypes as gatekeepers: increasing girls' interest in computer science and engineering by diversifying stereotypes. Frontiers in Psychology, $6(49)$.

Commonwealth of Australia, \& Australian Workforce and Productivity Agency. (2013). Information and communications technology workforce study. Retrieved from Australia: http://www.awpa.gov.au/

Crockett, L., Jukes, I., \& Churches, A. (2012). Literacy is not enough: 21st century fluencies for the digital age: Australia: Hawker Brownlow Education.

Deloitte. (2016). Technology, media \& telecommunications predications 2016. Retrieved from http://www2.deloitte.com/content/dam/Deloitte/global/Documents/Technology-MediaTelecommunications/gx-tmt-prediction-2016-full-report.pdf

Deloitte Access Economics. (2015). Australia's digital pulse: Key challenges for our nation: Digital skills, jobs and education. Retrieved from Australia: http://www2.deloitte.com/content/dam/Deloitte/au/Documents/Economics/deloitte-au-economicsaustralias-digital-pulse-240614.pdf

Deloitte Access Economics. (2016). Australia's digital pulse - Developing the digital workforce to drive growth in the future 2016. Retrieved from Australia: http://www2.deloitte.com/content/dam/Deloitte/au/Documents/Economics/deloitte-au-economicsdigital-pulse-2016-acs-110316.pdf

Dickhäuser, O., \& Stiensmeier-Pelster, J. (2003). Gender differences in the choice of computer courses: Applying an expectancy-value model. Social Psychology of Education, 6(3), 173-189. doi:10.1023/A:1024735227657

Fiebig, J. N., \& Beauregard, E. (2011). Longitudinal change and maternal influence on occupational aspirations of gifted female American and German adolescents. Journal for the Education of the Gifted, 34(1), 45-67.

Galyani Moghaddam, G. (2010). Information technology and gender gap: Toward a global view. The Electronic Library, 28(5), 722-733.

Gillard, H., Mitev, N., \& Scott, S. (2007). ICT inclusion and gender: Tensions in narratives of network engineer training. The Information Society, 23(1), 19-37.

Glass, R. L. (2012). The gender gap: Does it include information systems? Information Systems Management, 29, 83-84.

Google. (2014). Women who choose computer science-What really matters. Retrieved from http://static.googleusercontent.com/media/www.wenca.cn/en/us/edu/pdf/women-who-choose-whatreally.pdf

Hargittai, E., \& Shafer, S. (2006). Differences in actual and perceived online skills: The role of gender. Social Science Quarterly, 87(2), 432-448.

Hart, K. C., \& Stockdale, R. (2009). Exploring the gender divide: Perceptions of IT professionals in New Zealand. Paper presented at the CONF-IRM 2009, New Zealand.

Herring, C. (2009). Does diversity pay?: Race, gender, and the business case for diversity. American Sociological Review, 74(2), 208-224.

Hilbert, M. (2011). Digital gender divide or technologically empowered women in developing countries? A typical case of lies, damned lies, and statistics. Paper presented at the Women's Studies International Forum.

Howcroft, D., \& Trauth, E. M. (2008). The implications of a critical agenda in gender and IS research. Information Systems Journal, 18(2), 185-202.

Hutchinson, J., \& Tadros, E. (2014). Shortage of IT graduates a critical threat [Press release]. Retrieved from http://www.afr.com/p/technology/shortage of it graduates_critical tOuFEdBporFCdLIonKFJFJ 
Keane, T., Keane, W. F., \& Blicblau, A. S. (2016). Beyond traditional literacy: Learning and transformative practices using ICT. Education and Information Technologies, 21(4), 769-781.

Koppi, T. J., Naghdy, F., Chicharo, J. F., Sheard, J., Edwards, S., \& Wilson, D. (2008). The crisis in ICT education: An academic perspective. Paper presented at the Annual Conference of the Australasian Society for Computers in Learning in Tertiary Education, Melbourne. Retrieved from http://www.ascilite.org/conferences/melbourne08/procs/koppi-poster.pdf

Lawson, K. M., Crouter, A. C., \& McHale, S. M. (2015). Links between family gender socialization experiences in childhood and gendered occupational attainment in young adulthood. Journal of Vocational Behavior, 90, 26-35.

McKay, J., \& Marshall, P. (2007). Driven by two masters, serving both: The interplay of problem sloving and research in Information Systems action research project. In N. Kock (Ed.), An applied view of emerging concepts and methods (pp. 131-158). Laredo Texas: Springer.

Milman-Hurst, D. (2011). Mind the gender gap in technology. Recruiter. Retrieved from http://www.recruiter.co.uk/archive/part-28/Mind-the-gender-gap-in-technology/

NCWIT (Producer). (2014). Women and information technology by the numbers. Retrieved from http://www.ncwit.org/sites/default/files/resources/btn_02282014web.pdf

OECD. (2014). Education at a glance 2014: OECD indicators. Retrieved from http://dx.doi.org/10.1787/eag-2014-en

OECD. (2015a). The ABC of gender equality in education aptitude, behaviour, confidence, PISA. Retrieved from http://dx.doi.org/10.1787/9789264229945-en

OECD. (2015b). Students, computers and learning: Making the connection, PISA. Retrieved from http://dx.doi.org/10.1787/9789264239555-en

Paa, H. K., \& McWhirter, E. H. (2000). Perceived influences on high school students' current career expectations. The Career Development Quarterly, 49(1), 29-44.

Panko, R. R. (2008). IT employment prospects:Bbeyond the dotcom bubble. European Journal of Information Systems, 17(3182-3197).

Parameswaran, M., \& Whinston, A. B. (2007). Research Issues in Social Computing. Journal of the Association for Information Systems, 8(6), 336-350.

Patton, M. Q. (2002). Qualitative research \& evaluation methods (3rd ed.). Thousand Oaks, California: Sage Publications.

Quesenberry, J. L., \& Trauth, E. M. (2012). The (dis)placement of women in the IT workforce: An investigation of individual career values and organisational interventionsl. Information Systems Journal, 22, 457-473.

Ridley, G., \& Young, J. (2012). Theoretical approaches to gender and IT: Examining some Australian evidence. Information Systems Journal, 22, 355-373.

Sáinz, M., \& Eccles, J. (2012). Self-concept of computer and math ability: Gender implications across time and within ICT studies. Journal of Vocational Behavior, 80(2), 486-499.

Sáinz, M., Pálmen, R., \& García-Cuesta, S. (2012). Parental and secondary school teachers' perceptions of ICT professionals, gender differences and their role in the choice of studies. Sex Roles, 66(3-4), 235249.

Singh, K., Allen, K. R., Scheckler, R., \& Darlington, L. (2007). Women in computer-related majors: A critical synthesis of research and theory from 1994 to 2005. Review of Educational Research, 77(4), 500-533.

Thomas, T., \& Allen, A. (2006). Gender differences in students' perceptions of information technology as a career. Journal of Information Technology Education, 5, 165-176. Retrieved from https://www.informingscience.org/Publications/241 
Trauth, E. M., Quesenberry, J. L., \& Morgan, A. J. (2004). Understanding the under representation of women in IT: Toward a theory of individual differences. Paper presented at the SIGMIS'04, Tucson, Arizona, USA.

Vitores, A., \& Gil-Juárez, A. (2015). The trouble with 'women in computing': A critical examination of the deployment of research on the gender gap in computer science. Journal of Gender Studies, 1-15.

Wang, J., Hong, H., Ravitz, J., \& Ivory, M. (2015). Gender differences in factors influencing pursuit of computer science and related fields. Paper presented at the Proceedings of the 2015 ACM Conference on Innovation and Technology in Computer Science Education.

Wellington, J. (2000). Educational research: Contemporary issues and practical approaches. London: Biddles Ltd.

Whiston, S. C., \& Keller, B. K. (2004). The influences of the family of origin on career development: A review and analysis. The Counseling Psychologist, 32(4), 493-568.

Yansen, G. Z., Mariano. (2014). Why don't women program? Exploring links between gender, technology and software. Science, Technology \& Society, 19(3), 305-329. doi:10.1177/0971721814548111

Zagami, J., Boden, M., Keane, T., Moreton, B., \& Schulz, K. (2015). Girls and computing: Female participation in computing in Schools. Australian Educational Computing, 30(2).

\section{Biographies}

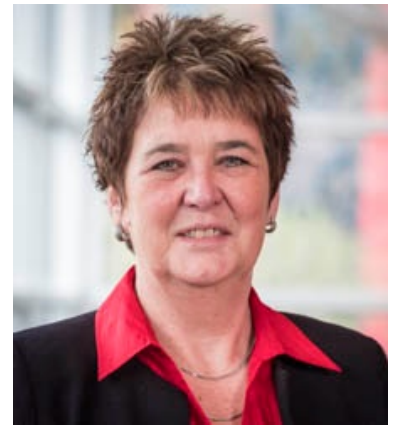

Professor Rosemary Stockdale is currently Department Chair of the Department of Business Technology and Entrepreneurship in the Faculty of Business and Law at Swinburne University of Technology. Rosemary has a PhD in Management Information Systems from Edith Cowan University, Perth. She has worked in several universities including Edith Cowan University, the Institute of IT and Tourism at Innsbruck University in Austria, Massey University in NZ and in 2013 she was a visiting professor at ESSEC Business School in Paris.

Rosemary's research interests include online communities, the effect of IT on organizational relationships, the use of social media in organizations and Women in ICT. She is also currently supervising several PhD students in the area of egovernment and Gov 2.0. She has published over 80 papers and book chapters in Information Systems, is the associate editor of two journals and a frequent reviewer for IS journals.

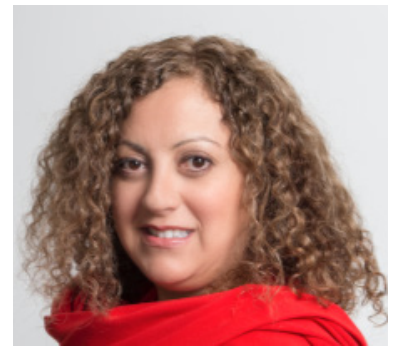

Dr. Therese Keane is a senior lecturer at Swinburne University's Department of Education. Therese has worked in a variety of school settings where she taught IT and was the Director of ICT. She holds a Doctorate in Education focusing on ICT Leadership in secondary schools. Therese is a Board member of both the Australian Computer Society's (ACS) ICT Educators Board and the Australian Council of Computers in Education (ACCE). She has presented numerous seminars and workshops for teachers involved in the teaching of IT.

Therese has written several textbooks in all units of VCE Information Technology since 1995 and has worked with the Victorian Curriculum and Assessment Authority (VCAA) in the development of the VCE Computing Study Design and various roles associated with VCE assessment over the past 20 years. Therese's current works involves the provision of professional development to ICT teachers and research into the use of technology, gender inequalities in STEM based subjects, robotics in education and computers in schools for teaching and learning purposes. 